\title{
Substantiation of the parameters of the feeder chamber conveyor of the combine harvester header
}

\author{
Kukhmaz Kukhmazov ${ }^{1, *}$ and Vladimir Konovalov ${ }^{2}$ \\ ${ }^{1}$ Penza State Agrarian University, 30, Botanicheskaya St., 440014, Penza, Russia \\ ${ }^{2}$ Penza State Technological University, 1A/11, proyezd Baydukova/Gagarina St., 440039, Penza, \\ Russia
}

\begin{abstract}
The aim of the research was to check the possibility of using and the justification of design and operating parameters of the proposed chain-and-slat conveyor of the feeder house for harvesting grain crops on the example of wheat. The research methodology included the determination of grain losses and crushing behind the combine thresher when varying the slat pitch of the chain-and-slat transporter $(153.6 ; 307.2$ and $460.8 \mathrm{~mm})$, the speed of moving these slats $(2.0 \ldots 5.0 \mathrm{~m} / \mathrm{s})$ and the speed of the combine $(1.2 \ldots 2.4 \mathrm{~m} / \mathrm{s})$. The researches made on chain-andslat conveyor of the combine harvester's feeder house have shown that it can be used in the harvester's design. The rational values of design and mode parameters of chain-and-slat conveyor of the combine harvester's feeder house have been justified by laboratory and field studies. At a pitch of stamped slats of the chain-and-slat conveyor of $307.2 \mathrm{~mm}$, a speed of chain-and-slat conveyor slats of $2.8 \ldots 3.6 \mathrm{~m} / \mathrm{s}$ and a working speed of the combine of $2.2 \mathrm{~m} / \mathrm{s}$, grain losses behind the threshing machine and grain crushing amount to less than one percent that meets the agricultural requirements.
\end{abstract}

\section{Introduction}

Grain harvesting is the most stressful and responsible stage in the cultivation of grain and leguminous crops. Industry produces a large and diverse number of combine harvester designs with different headers [1].

In many respects the load of combine harvester mechanisms and its engine is determined by parameters of the header and the speed of the combine harvester [2]. At the same time the operation of all elements of combine harvester affects the quality of its work, including grain crushing and losses. The grain crushing value is also influenced by the variety and type of crop [3]. Therefore, there is a need to improve the performance of the combine harvester and its cutterbar, including the improvement of the header elements design and the modes of their operation [4].

\footnotetext{
*Corresponding author: konovalov-penza@rambler.ru
} 
Because of the unevenness of the field and the unevenness of the combine harvester's movement, and due to the design of the header components, there are forced and natural vibrations in the header, which affect its operation [5].

Various mechanisms and control systems are used to organize the normal operation of the header. In order to maintain a constant cutting height of the plants, mechanisms to copy the soil surface of the field are used [6]. To take into account the height of plants, the intensity of their arrival in the header, intelligent control systems of their harvesting are developed [7, 8].

Adjusting the working speed of the combine harvester and the reel speed can help reduce crop and/or grain loss [9]. The reel radius and the ratio of the speed of the reel to the speed of the combine harvester are also important [10]. The energy consumption of headers and the quality of the crop stalk cutting are influenced by the design of the cutterbar and the speed ratio of the header to the combine [11]. Additional active cutting elements can be used on the side of the header to separate the cut plants from the main mass [12, 13]. This can affect energy and raw material losses. The results of operational tests have shown that the application of wear-resistant electrospark coating on the working bodies can improve their wear resistance and reliability of the machines, and increase their service life [14].

In order to increase the productivity of the header, its working width is increased [15]. This affects, among other things, the operation of transporting working bodies of the header and the value of losses of the harvested crop.

An important component of a combine harvester, providing for the pulling of stalks from the auger finger mechanism and their uniform feeding into the threshing unit of the combine harvester, is the feeder house conveyor [16]. The most widespread are chain-andslat conveyors. It has been found that the technological process of the combine harvester as a whole (and the chain-and-slat conveyor in particular) does not always run stably, which causes uneven feeding of the stalk mass into the thresher of the combine harvester.

This, in turn, leads to clogging of the working elements of threshing machine, increases power consumption, reduces productivity and deteriorates the quality indicators of the entire combine harvester, increases energy intensity of threshing process [16].

The purpose of the research was to check the possibility of using and justification of design and operating parameters of the proposed chain-and-slat conveyor of the feeder house in harvesting cereal crops with wheat as an example.

\section{Methods and Materials}

In single-phase grain harvesting, the initial condition of the stalks entering the header's feeder house has a minimum thickness in the middle of the flow and a maximum at the edges. For a more uniform feeding of the stem mass into the threshing unit, thereby minimizing the losses and crushing of grain, it is proposed to use the chain-and-slat conveyor of the feeder house, consisting of four parallel sleeve-roller chains 1 (Figure 1) with a pitch of $38.4 \mathrm{~mm}$, to which the fastening plates 3 are connected via rivets. The stamped metal strips 2 are connected to the plates 3 via screw connections 4 . The slats are $540 \mathrm{~mm}$ long. The distance between the two middle chains is $443 \mathrm{~mm}$ and the distance between the outermost and the nearest middle chain is $386 \mathrm{~mm}$. The outermost end of the stamped metal strip is $105 \mathrm{~mm}$ from the centre of the outermost chain. At the outer ends of the two stamped slats of each outermost row there are pins 5, designed to prevent the sides of the inclined body from being clogged with stalk mass. The total width of the chain-andslat conveyor belt is $1420 \mathrm{~mm}$ and its length is $3379 \mathrm{~mm}$ ( 88 links). The stamped slats 4 are attached to the sleeve-roller chains in three rows in a staggered arrangement. 


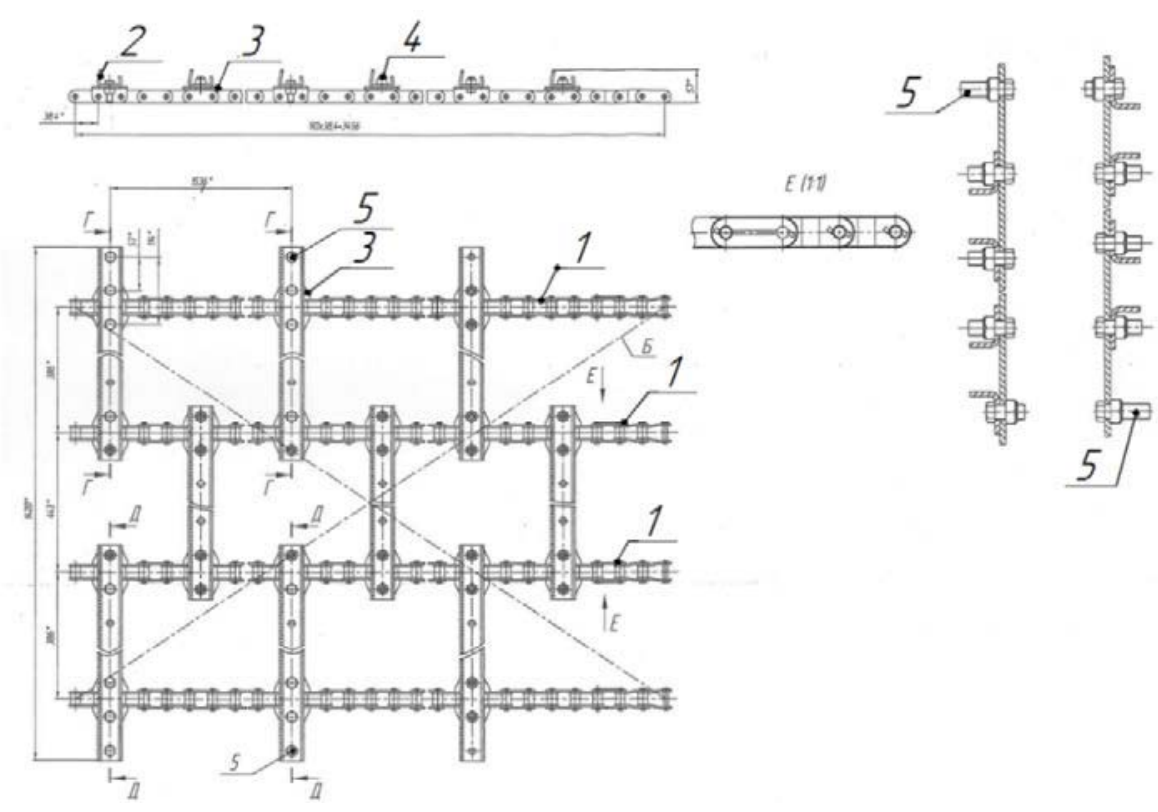

Fig. 1. Chain-and-slat conveyor: 1 - conveyor chain; 2 - stamped slat; 3 - fastening plate; 4 - screw connection; 5 - pin.

In order to justify the design and mode parameters of the proposed chain-and-slat conveyor, laboratory and field studies were carried out under real conditions of OOO "Russkoe Pole" (LLC), Serdobsky district, Penza region (RU) on the header of an Akros 585 harvester of OOO "Combine Plant "Rostselmash" (Russia). The stalk yield of wheat was $3.3 \mathrm{t} / \mathrm{ha}$. The objective of the research was to study dependence of grain losses $(\mathrm{L}, \%)$ and crushing $(\mathrm{C}, \%)$ behind the threshing machine on the pitch of stamped slats of the chain-and-slat conveyor $(\mathrm{t}, \mathrm{mm})$; the speed of chain-and-slat conveyor $(\mathrm{v}, \mathrm{m} / \mathrm{s})$ and the working speed of the combine $\left(\mathrm{V}_{\mathrm{k}}, \mathrm{m} / \mathrm{s}\right)$.

To determine the grain losses behind the combine thresher, the outgoing straw and chaff were placed in a swath. Fifty ears were taken from the swath and the unthreshed grains were threshed by hand. The grain losses were determined according to the formula:

$$
\mathrm{L}=\frac{\mathrm{k} \cdot \mathrm{N} \cdot \mathrm{A}}{5000 \cdot \mathrm{h}} \cdot 100 \%
$$

where $\mathrm{k}$ - the number of non-soaked grains in 50 ears, pcs; $\mathrm{N}$ - the density of productive stand, $\mathrm{pcs} / \mathrm{m}^{2}$; A - the weight of 1000 grains, $\mathrm{g}$; $\mathrm{h}$ - the yield of grain, cwt/ha.

To determine the percentage of crushed grains (C, \%) a sample of about $20 \mathrm{~cm}^{3}$ was taken from the hopper of the combine, the impurities were separated and the grains were sorted into whole and crushed ones. The crushed particles were converted into whole grains by dividing the number of crushed particles by two or three (depending on the prevalence of halves or thirds). The resulting number of crushed grains was divided by the total number of grains in the sample and multiplied by 100 .

The parameter justification was carried out in several stages. In the first stage, three versions of the chain-and-slat conveyor with different chain pitches were installed alternately in the header house. There were made three chain-and-slat conveyors with the slat pitches of: $153.6 ; 307.2$ and $460.8 \mathrm{~mm}$. When investigating the influence of stamped slat pitch $t$ on the uniformity of feeding, and accordingly on the losses (L, \%) and crushing $(\mathrm{C}, \%)$ of grain, all parameters and operating mode of the chain-and-slat conveyor, except for the slat pitch, remained constant. The speed of the chain-and-slat conveyor was $v=3.5$ 
$\mathrm{m} / \mathrm{s}$, the working speed of the combine $\mathrm{V}_{\mathrm{k}}=1.8 \mathrm{~m} / \mathrm{s}$. In the second stage, the selected chain-and-slat conveyor was used and the speed of the chain-and-slat conveyor and the working speed of the combine varied. The speed of the slats varied from 2.0 to $5.0 \mathrm{~m} / \mathrm{s}$ by using replaceable sprockets. The combine speed varied from 1.2 to $2.4 \mathrm{~m} / \mathrm{s}$.

During processing of results of experiment, the programs Excel, MathCAD, Statictica were used.

\section{The Results of the Studies}

According to the results of processing the experimental data (Table 1) histograms of the losses $(\mathrm{L}, \%)$ and crushing of grain $(\mathrm{C}, \%)$ depending on the pitch of the stamped slats of the conveyor $t(\mathrm{~mm}$, Figure 2) were made.

As the data show, with increasing the pitch of the stamped slats $t$ more than $307.2 \mathrm{~mm}$, both losses and crushing of grain sharply increase. The best quality indexes are given at the smallest slat pitches $t=153.6 \ldots 307.2 \mathrm{~mm}$. The values of grain loss and crushing in this case practically do not change, within the margin of error of experience. For further researches we accept $t=307.2 \mathrm{~mm}$ due to lower metal intensity of the chain-and-slat conveyor.

Table 1. The results of studies on the effect of the pitch of the chain-and-slat elevator on grain loss and crushing.

\begin{tabular}{|l|c|c|c|}
\hline Slat pitch t, mm & 153.6 & 307.2 & 460.8 \\
\hline Losses L, \% & 0.28 & 0.35 & 1.16 \\
\hline Crushing C, \% & 0.40 & 0.35 & 0.85 \\
\hline
\end{tabular}

When determining rational values for the speed of the chain-and-slat conveyor into the feeder' house, a slat spacing of $t=307.2 \mathrm{~mm}$ was installed. All other parameters, except the speed of the slats $v$, remained the same.

Further, according to the results of processing the experimental data (Table 2), the diagrams of dependence of the losses $(\mathrm{L}, \%)$ and crushing of grain $(\mathrm{C}, \%)$ on the speed of the chain-and-slat conveyor $v$ were built (Figure 3 ). The regression equations of grain losses and crushing:

$$
\begin{gathered}
\mathrm{L}=2.1479-1.08476 \cdot \mathrm{v}+0.17619 \cdot \mathrm{v}^{2} \\
\mathrm{C}=2.168-1.181 \cdot \mathrm{v}+0.2 \cdot \mathrm{v}^{2}
\end{gathered}
$$

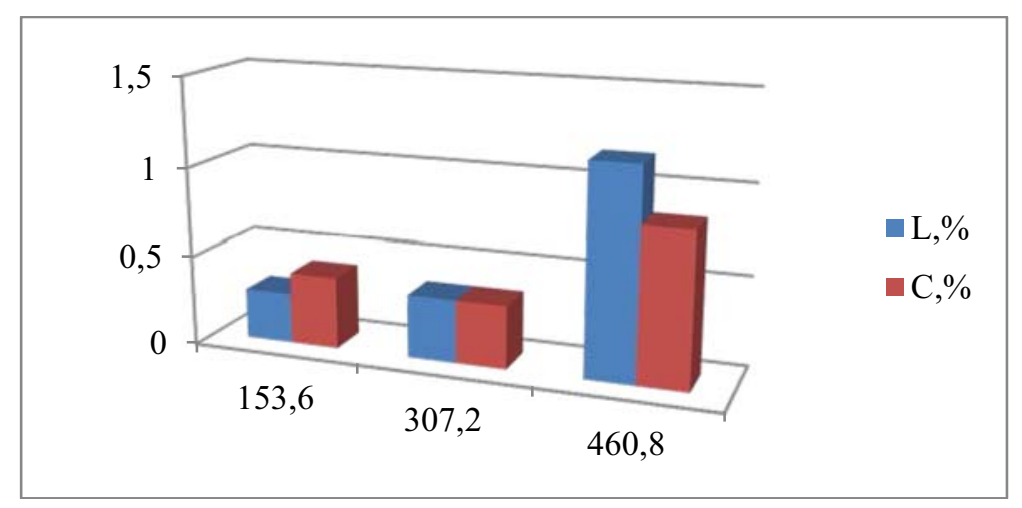

Fig. 2. The dependence of grain losses $(\mathrm{L}, \%)$ and crushing $(\mathrm{C}, \%)$ on the pitch of the stamped chain slats $(\mathrm{t}, \mathrm{mm})$.

The correlation coefficients of the specified regression equations are $\mathrm{R}=0.99240$ and $\mathrm{R}=0.99280$. The F-test data are 0.985698 and 0.986446 (respectively), also the graphs of 
correspondence of calculated and experimental values (Figure 4) testify to adequacy of the obtained models.

The lowest grain loss and crushing are achieved at a conveyor belt speed of around 3 $\mathrm{m} / \mathrm{s}(2.8$ to $3.6 \mathrm{~m} / \mathrm{s})$. Deviations from this speed increase unproductive grain losses.

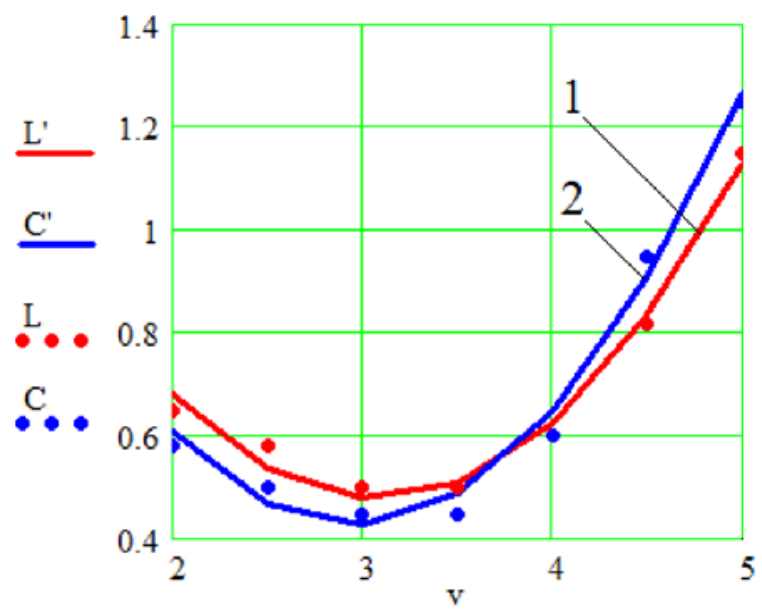

Fig. 3. The dependence of grain losses (L, \%) and crushing (C, \%) on the speed of chain-and-slat conveyor slats $(v, \mathrm{~m} / \mathrm{s}): 1$ - the regression function of grain losses L; 2 - the regression function of grain losses $\mathrm{C}^{\prime}$; $\mathrm{L}, \mathrm{C}$ - experimental values of grain losses and crushing (points).

Table 2. The results of studies on the effect of chain-and-slat conveyor slat speed on the grain losses and crushing.

\begin{tabular}{|l|c|c|c|c|c|c|c|}
\hline Conveyor speed v, m/s & 2.0 & 2.5 & 3.0 & 3.5 & 4.0 & 4.5 & 5.0 \\
\hline Losses L, \% & 0.65 & 0.58 & 0.50 & 0.50 & 0.60 & 0.82 & 1.15 \\
\hline Crushing C, \% & 0.58 & 0.50 & 0.45 & 0.45 & 0.60 & 0.95 & 1.25 \\
\hline
\end{tabular}

The research to determine the rational values of the combine's working speed $V_{k}$ was carried out taking into account the previously justified parameters and operating mode of the chain-and-slat conveyor, which ensured the best performance. Table 3 shows the results of the experiment. The regression equations of grain losses and crushing (Figure 5):

$$
\begin{gathered}
L=0.934-0.91964 \cdot v+0.42559 \cdot v^{2} ; \\
C=2.205-2.316 \cdot v+0.777 \cdot v^{2} .
\end{gathered}
$$

The correlation coefficients of the specified regression equations are $\mathrm{R}=0.99481$ and $\mathrm{R}=0.98926$. The F-test data are 0.990239 and 0.979751 (respectively), also the graphs of correspondence of calculated and experimental values (Figure 6) testify to adequacy of the obtained models.

The results obtained (Figure 5) show that at the working speed of the combine $\mathrm{V}_{\mathrm{k}}$ of less than $2.2 \mathrm{~m} / \mathrm{s}$, grain fragmentation behind the thresher does not exceed $0.9 \%$, and the grain losses are less than $1.0 \%$, which complies with the agricultural technical requirements. Further increase of combine's working speed leads to the increase of losses and crushing of grain due to the impairment of uniformity of stem mass feeding into the threshing unit of the combine. Reducing the speed of the combine reduces both types of loss, but will significantly reduce the productivity of the harvesting equipment. 


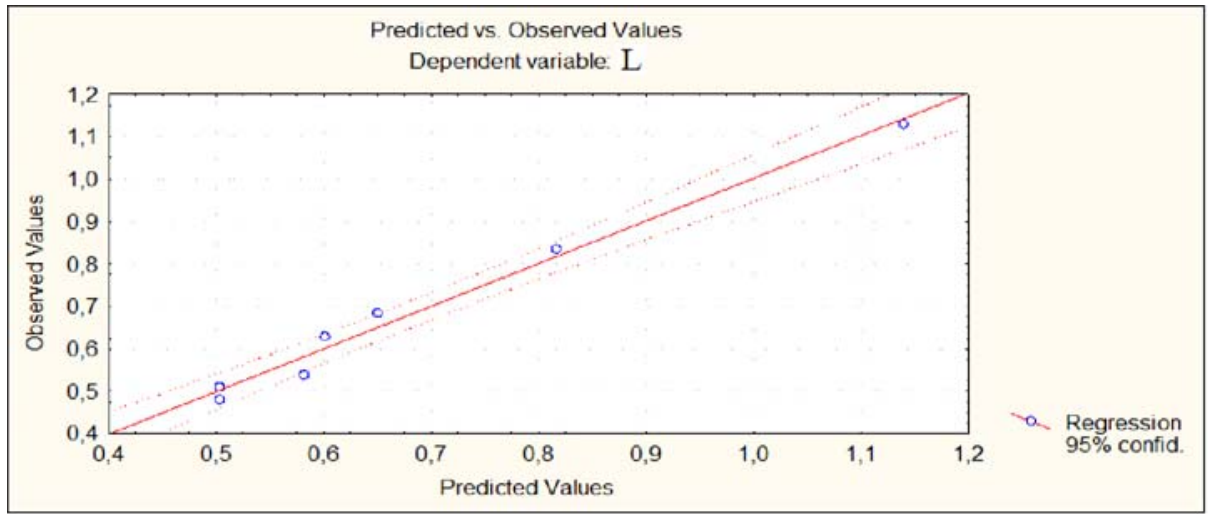

(a)

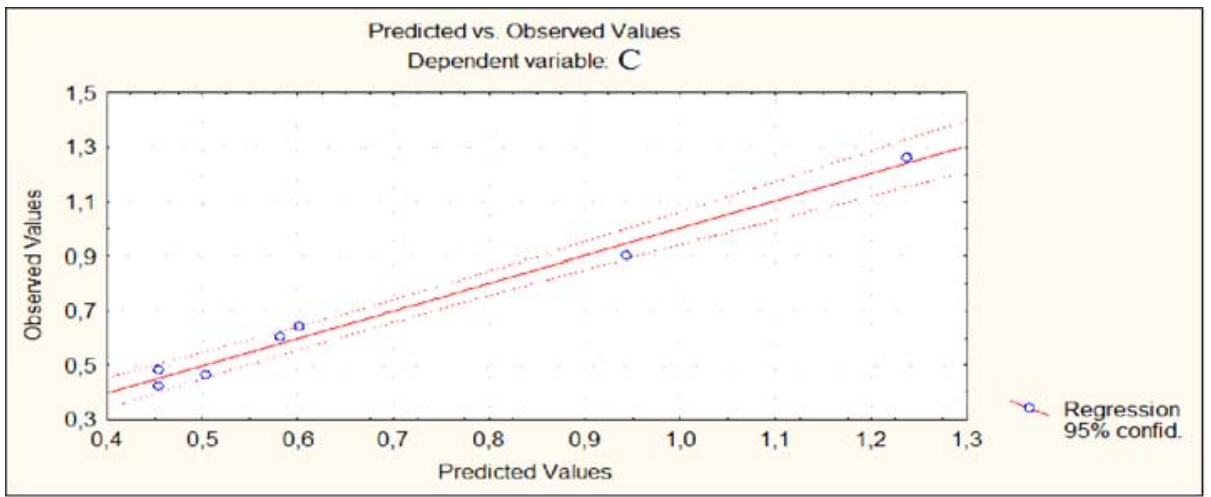

(b)

Fig. 4. The graph of correspondence of calculated and experimental values: (a) - grain losses (L, \%); (b) - grain crushing $(\mathrm{C}, \%)$.

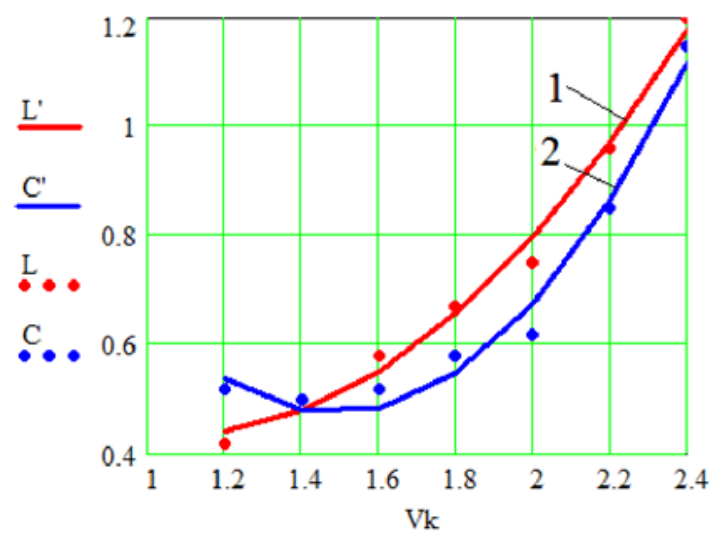

Fig. 5. The dependence of grain losses $(\mathrm{L}, \%)$ and crushing $(\mathrm{C}, \%)$ on combine's working speed $\left(\mathrm{V}_{\mathrm{k}}\right.$, $\mathrm{m} / \mathrm{s}$ ): 1 - the regression function of grain losses $\mathrm{L}^{`} ; 2$ - the regression function of grain losses $\mathrm{C}^{`} ; \mathrm{L}, \mathrm{C}$ - the experimental values of grain losses and crushing (points).

Table 3. The results of studies on the effect of combine speed on grain loss and crushing.

\begin{tabular}{|l|c|c|c|c|c|c|c|}
\hline Combine speed Vk, m/s & 1.2 & 1.4 & 1.6 & 1.8 & 2.0 & 2.0 & 2.4 \\
\hline Losses L, \% & 0.42 & 0.50 & 0.58 & 0.67 & 0.75 & 0.96 & 1.2 \\
\hline Crushing C, \% & 0.52 & 0.50 & 0.52 & 0.58 & 0.62 & 0.85 & 1.15 \\
\hline
\end{tabular}




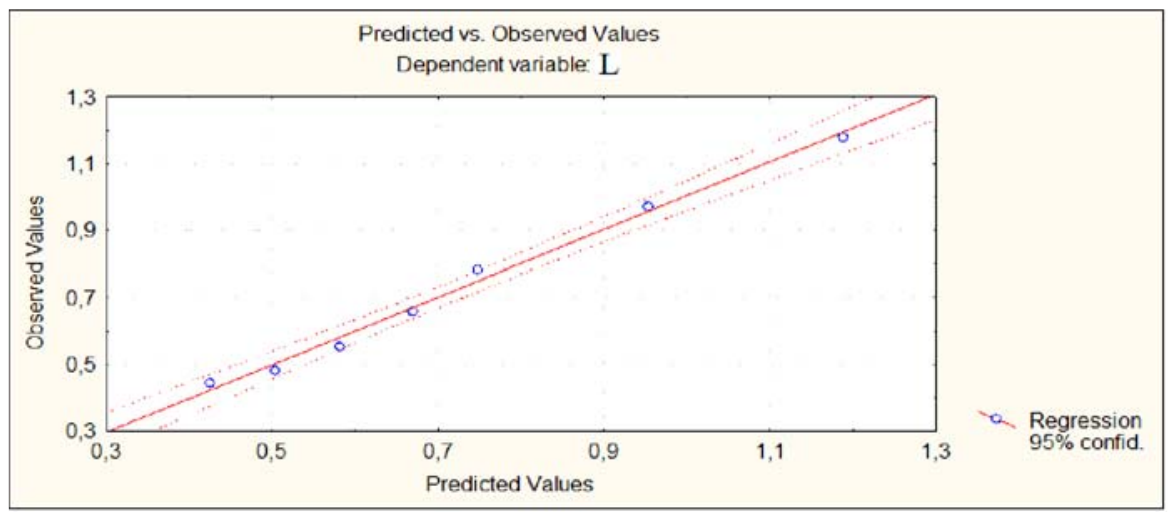

(a)

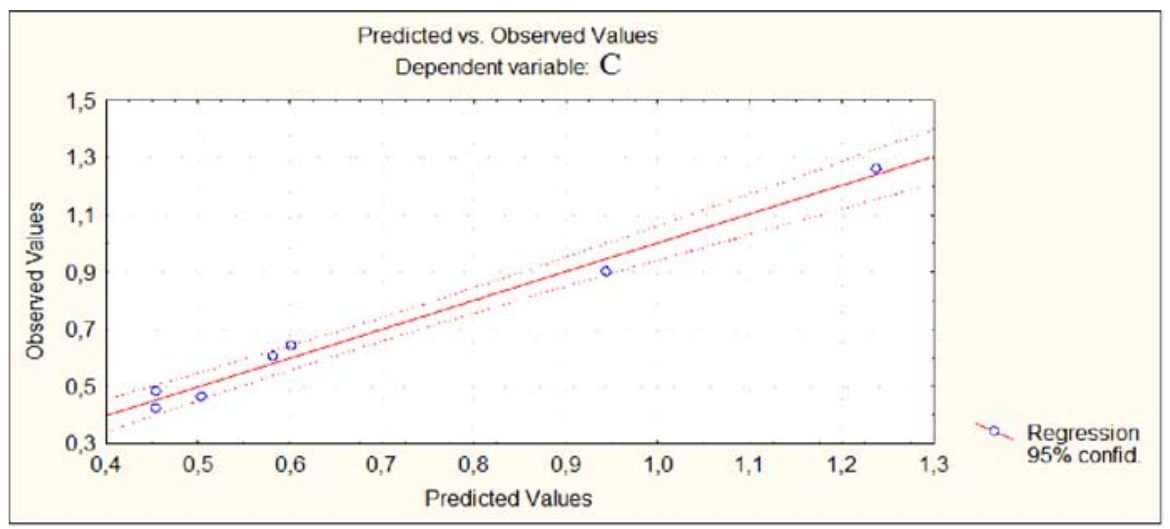

(b)

Fig. 6. The graph of correspondence of calculated and experimental values: (a) - grain losses (L, \%); (b) - grain crushing $(\mathrm{C}, \%)$.

\section{Conclusion}

The performed laboratory and field researches of the chain-and-slat conveyor of the combine harvester's feeder house have shown the possibility of its use in the harvester's design. The rational values of design and mode parameters are justified. Thus, at a pitch of stamped slats of the chain-and-slat conveyor of $307.2 \mathrm{~mm}$, its speed of $2.8 \ldots .3 .6 \mathrm{~m} / \mathrm{s}$ and the combine's working speed of $2.2 \mathrm{~m} / \mathrm{s}$, the loss and crushing of the grain behind the threshing unit of the combine is below one percent that meets the agricultural technical requirements.

\section{References}

1. V.L. Astaf, V.A. Golikov, E.V. Zhalnin, S.A. Pavlov, AMA, Agricultural Mechanization in Asia, Africa and Latin America 51(3), 46-51 (2020) https://jglobal.jst.go.jp/en/detail?JGLOBAL_ID=202002246521566465

2. Y. Sun, R. Liu, H. Ou, C. Zhang, M. Zhang, H. Li, Nongye Jixie Xuebao/Transactions of the Chinese Society for Agricultural Machinery 51(5), 118 123 (2020) DOI :10.6041/j.issn.1000-1298.2020.05.012

3. E. Lei, D. Shao, T.-B. Zhu, X. Shu, Y.B. Yang, Y.-D. Wang, Q.-Y. Tang, Acta Prataculturae Sinica 29(9), 125-135 (2020) DOI: 10.11686/cyxb2019517 
4. W. Stefanoni, F. Latterini, J.P. Ruiz, S. Bergonzoli, C. Attolico, L. Pari, Energies 13(20), 5329 (2020) DOI: 10.3390/en13205329

5. Z. Xue, X. Chen, H. Tang, M. Li, Journal of Physics: Conference Series 1635(1), 012030 (2020) doi:10.1088/1742-6596/1635/1/012030

6. K. Kukhmazov, V. Konovalov, A. Malyshev, E3S Web of Conferences 164, 06010 (2020) https://doi.org/10.1051/e3sconf /2020164060

7. Z. Zhang, R. Chi, N. Dong, Yu. Du, X. Li, B. Xie, Applied Sciences (Switzerland) 10(24)-8888, 1-15 (2020) DOI: 10.3390/app10248888

8. A. Geng, M. Zhang, J. Zhang, A. Gao, J. Zheng, Nongye Jixie Xuebao/Transactions of the Chinese Society for Agricultural Machinery 51, 118-125 (2020) DOI:10.6041/j.issn.1000-1298.2020.S2.014

9. W. Stefanoni, F. Latterini, J.P. Ruiz, S. Bergonzoli, N. Palmieri, L. Pari, Sustainability (Switzerland) 13(1)-195, 1-11 (2021) DOI: 10.3390/su13010195

10. X. Zhuang, Y. Li, IOP Conference Series: Materials Science and Engineering 740(1), 012208 (2020) DOI: 10.1088/1757-899X/740/1/012208

11. J. Ran, S. Mu, H. Li, Z. Guan, Q. Tang, C. Wu, Nongye Gongcheng Xuebao / Proceedings of the Chinese Society of Agricultural Engineering 36(9), 17-25 (2020) DOI: 10.11975 / j.issn.1002-6819.2020.09.002

12. Z. Guan, C. Wu, Y. Li, S. Mu, L. Jiang, Science Progress 103(3) (2020) https://doi.org/10.1177/0036850420935728

13. M. Huang, Y. Li, A. Chen, L. Xu, Applied Sciences (Switzerland) 10(13), 4432 (2020) DOI: 10.3390/app10134432

14. S.A. Velichko, S.N. Sharifullin, I.S. Kuznetsov, A.V. Kolomeichenko, R.Y. Solovyev, I.N. Kravchenko, N. R. Adigamov, IOP Conference Series: Materials Science and Engineering 915(1), 012045 (2020) doi:10.1088/1757-899X/915/1/012045

15. V. Dimitrov, L. Borisova, I. Nurutdinova, E3S Web of Conferences 175, 05027 (2020) https://doi.org/10.1051/e3sconf/202017505027

16. Zh.S. Baizakova, Siberian herald of agricultural science (Novosibirsk) 2(225), 116-121 (2012) https://www.elibrary.ru/item.asp?id=17729515 